\title{
ANALISIS PENERAPAN E-FILING PADA WAJIB PAJAK ORANG PRIBADI DI KPP PRATAMA BITUNG
}

\author{
Yuyun Meisiang ${ }^{1}$, Jullie J. Sondakh ${ }^{2}$, Jessy D.L Warongan ${ }^{3}$ \\ 1,2,3 Jurusan Akuntansi, Fakultas Ekonomi dan Bisnis Universitas Sam Ratulangi, J1. Kampus Bahu, Manado, \\ 95115, Indonesia \\ E-mail : yunmeisiang@gmail.com
}

\begin{abstract}
To increase state tax revenue, the Directorate General of Taxes conducts administrative reforms in the field of taxation by implementing e-Filing, a means of reporting on Annual Individual Income Tax Returns online. The application of e-Filing is expected to facilitate Taxpayers to carry out tax obligations so as to increase state revenues. This study aims to analyze the application of e-Filing to Individual Taxpayers at Bitung Primary Tax Office. The sampling method in this study is a descriptive qualitative approach using primary and secondary data through observation of interviews with tax officers and individual taxpayers registered at the Bitung Primary Tax Office. The results of this study indicate that the implementation of e-Filing has not been effective enough, the number of Individual Taxpayers who used e-Filing in 2016 was 32,374 taxpayers, and there was a decline in 2017 of 29,477 taxpayers. The application of e-Filing will be maximum if the KPP Pratama Bitung increases socialization.
\end{abstract}

Keywords : E-Filing, implementation of e-filing, personal taxpayer.

\section{PENDAHULUAN}

Pajak adalah pendapatan utama suatu Bangsa untuk memenuhi pengeluaran pemerintah. Menurut APBN Pajak merupakan pendapatan terbesar Negara, sehingga pajak bisa membantu kesejahteraan masyarakat. Perubahan sistem administrasi pajak menjadi hal penting agar supaya setiap kebutuhan dan tuntutan pajak bisa terpenuhi. Kemajuan sistem perpajakan yang di buat untuk meningkatkan penerimaan negara di bidang perpajakan. Direktorat Jenderal Pajak membuat suatu sistem kebijakan yang modern guna mengoptimalkan penerimaan kas negara. Tepatnya pada tahun 2005 Presiden Indonesia meluncurkan e-Filing yang bertempat di Kantor Kepresidenan Indonesia.

$e$-Filing adalah suatu aplikasi pajak berbasis online yang di gunakan untuk melakukan penyampaian SPT Tahunan melalui jasa penyedia aplikasi atau Application Service Provider (ASP) . Untuk menggunakan aplikasi e-Filing maka jaringan internet merupakan salah satu hal utama yang di butuhkan untuk mengoperasikannya. Kelebihan yang di tawarkan oleh pelaporan SPT online ini membuat wajib pajak menjadi mudah melapor SPT Tahunan. Namun dalam dalam kenyataannya masih terdapat banyak WP yang tidak memakai $e$-Filing sebagai sarana untuk pelaporan SPT Tahunan. Kurangnya minat WP menggunakan e-Filing menyebabkan pelaporan SPT secara e-Filing tidak maksimal. Pengetahuan Wajib Pajak merupakan aspek penting dalam memaksimalkan e-Filing.

\section{TINJAUAN PUSTAKA}

Pengertian Akuntansi. Menurut Hans Kartikahadi, dkk. (2016:3) Akuntansi merupakan informasi yang berhubungan dengan keuangan dan memiliki tujuan agar bisa menghasilkan informasi yang akurat serta relevan bagi semua pihak.

Pengertian Akuntansi Perpajakan. Akuntansi Pajak ialah informasi keuangan yang berhubungan dengan pajak guna memudahkan penyususnan SPT masa dan Tahunan. 
Fungsi Akuntansi Pajak. Akuntansi Pajak menurut Waluyo (2014 : 35) merupakan dasar laporan keuangan yang menetapkan pajak terhutang oleh suatu perusahaan.

Pengertian Pajak. Pajak merupakan hutang wajib oleh orang pribadi atau badan kepada negara.

Wajib Pajak. Wajib Pajak yaitu meliputi penyetor pajak, pemungut pajak dan pemotong pajak oleh orang pribadi atau badan berdasarkan ketentuan yang berlaku.

Fungsi Pajak. Menurut Resmi (2014:3):

a. Fungsi Budgetair (Sumber Keuangan Negara). Yaitu unruk membiayai pengeluaran pemerintah.

b. Fungsi Regularend (Pengatur). Yaitu alat untuk mengatur pengeluaran pemerintah.

Jenis Pajak. Menurut Resmi (2014:7)Terdapat berbagai jenis pajak yang di kelompokkan sebagai berikut :

a. Berdasarkan Golongan

b. Berdasarkan Sifat

c. Berdasarkan Lembaga Pemungutan

Tarif Pajak. Menurut Resmi (2014:14) terbagi atas tiga :

a. Tarif Tetap

b. Tarif Proporsional (Sebanding)

c. Tarif Progresif (Meningkat)

Surat Pemberitahuan (SPT). Merupakan surat yang di gunakan oleh wajib pajak, yang tujuannya untuk menghitung harta dan kewajiban dan melaporkannya berdasarkan pada undang-undang.

Fungsi SPT. Menurut Diana (2013:193) Fungsi SPT untuk Wajib pajak ialah sebagai media pelaporan dan pertanggung jawaban perhitungan hasil pajak yang terutang.

E-Filing. e-Filing atau electronic filing system ialah pelaporan serta penyampaian SPT Tahunan secara online yang bisa di lakukan di mana saja dan kapan saja dengan memanfaatkan jaringan internet.

Latar Belakang E-Filing. Agar meminimalkan proses pelaporan SPT Tahunan yang memakan waktu lama, serta mengurangi penggunaan kertas dan menghemar biaya percetakan.

Prosedur Penggunaan $\boldsymbol{E}$-Filing. Adapun Prosedur yang digunakan dalam melaksanakan $e$ Filing yaitu :

1. Pengajuan Permohonan Untuk Mendapatkan EFIN (Electronic Filing Identification Number

a. Membuat permohonan e-FIN (Electronic Filing Identification Number) di KPP terdekat dengan melampirkan fotocopy kartu NPWP.

b. Permohonan akan di proses jika alamat sesuai dalam database.

c. Setelah permohonan e-FIN di ajukan, kepala KPP harus memberi keputusan paling lambat 2 (dua) hari sejak permohonan diterima (hari kerja).

d. Apabila e-FIN hilang, WP bisa mencetak kembali dengan menunjukkan NPWP.

2. Pendaftaran

a. Jika sudah mendapatkan e-FIN Wajib pajak bisa mendaftarkan diri melalui penyedia jasa aplikasi resmi DJP.

b. Setelah mendaftarkan diri WP akan memperoleh User ID dan Password.

3. Penyampaian $e$-SPT Secara $e$-Filing

a. Apabila telah mengunduh aplikasi e-Filing maka dapat di isi pada saat offline.

b. Apabila SPT telah di isi secara lengkap, wajib pajak bisa mengirim ke DJP.

Hal Penting Setelah Proses e-Filing.

a. Bukti Transaksi secara e-Filing

b. Masa Pemberlakuan $e$-Filing 
c. Penyempurnaan e-Filing.

Indikator $\boldsymbol{e}$-Filing. Indikator yang dipakai ialah penerapan e-Filing.

Sumber Daya Manusia. Menurut Hasibuan (2016) merupakan daya pikir dan daya fisik serta kemampuan terpadu yang di miliki individu.

Sosialisasi Perpajakan. Menurut Susanto dalam (Sugeng Wahono, 2012: 80). Sosialisasi pajak merupakan upaya DJP agar WP serta seluruh masyarakat bisa tahu mengenai perpajakan baik tata cara maupun peraturan perpajakan.

Indikator Sosialisasi Perpajakan. Sosialisasi Perpajakan dengan indikator menurut Arya Yogatama (2014) yaitu :
a. Tatacara Sosialisasi
b. Frekuensi Sosialisasi
c. Kejelasan Sosialisasi Pajak
d. Pengetahuan Perpajakan.

Penelitian Terdahulu. Tumuli (2016) dalam penelitiannya yang berjudul : Analisis Penerapan e-SPT dan e-Filing Dalam Upaya Peningkatan Kepatuhan Wajib Pajak (Studi Kasus di KPP Pratama Manado), untuk mengetahui tingkat penggunaan e-SPT dan e-Filing, serta kepatuhan wajib pajak yaitu ketetapan melapor pajak menggunakan e-SPT dan e-Filing di KPP Pratama Bitung. Metode penelitian kualitatif. Hasil penelitian yaitu jumlah presentase pengguna e-Filing meningkat. Di mana setiap tahunnya bertambah sehingga berdampak positif untuk kedepannya.

\section{METODE PENELITIAN}

Jenis Penelitian. Untuk menganalisis suatu penelitian atau hasil penelitian namun bukan dalam kesimpulan yang luas.

Tempat dan Waktu Penelitian. Lokasi penelitian yang dilaksanakan pada Kantor Pelayanan Pajak Pratama Bitung, yang beralamat Jalan Sam Ratulangi kota Bitung. Waktu penelitian yang dilaksanakan pada bulan Februari 2018-Juli 2018.

\section{Prosedur Penelitian.}

a. Membuat prosedur penelitian

b. Mendatangi lokasi penelitian

c. Melakukan wawancara dan dokumentasi

d. Menarik kesimpulan dari hasil penelitian.

Jenis Data. Jenis data yang digunakan oleh peneliti adalah penelitian Kualitatif . Menurut Kuncoro (2013), Data kualitatif adalah data yang disajikan dalam dalam bentuk uraian yang tidak dapat diukur dalam skala numerik.

Teknik Pengumpulan Data. Metode pengumpulan data yang digunakan dalam penelitian ini adalah sebagai berikut :

a. Wawancara, Menurut Moh. Nazir (2014:170-171) merupakan cara mendapatkan informasi melalui proses tanya jawab secara langsung dengan narasumber.

b. Metode Dokumentasi, ialah karya-karya berupa tulisan, gambar dari seseorang . Mengumpulkan data melalui dokumentasi yaitu membuat subjek sendiri dengan menggunakan analisis dokumen. 
Teknik Analisis Data. Analisis data yang digunakan yaitu model Miles dan Huberman (2012:15-19).

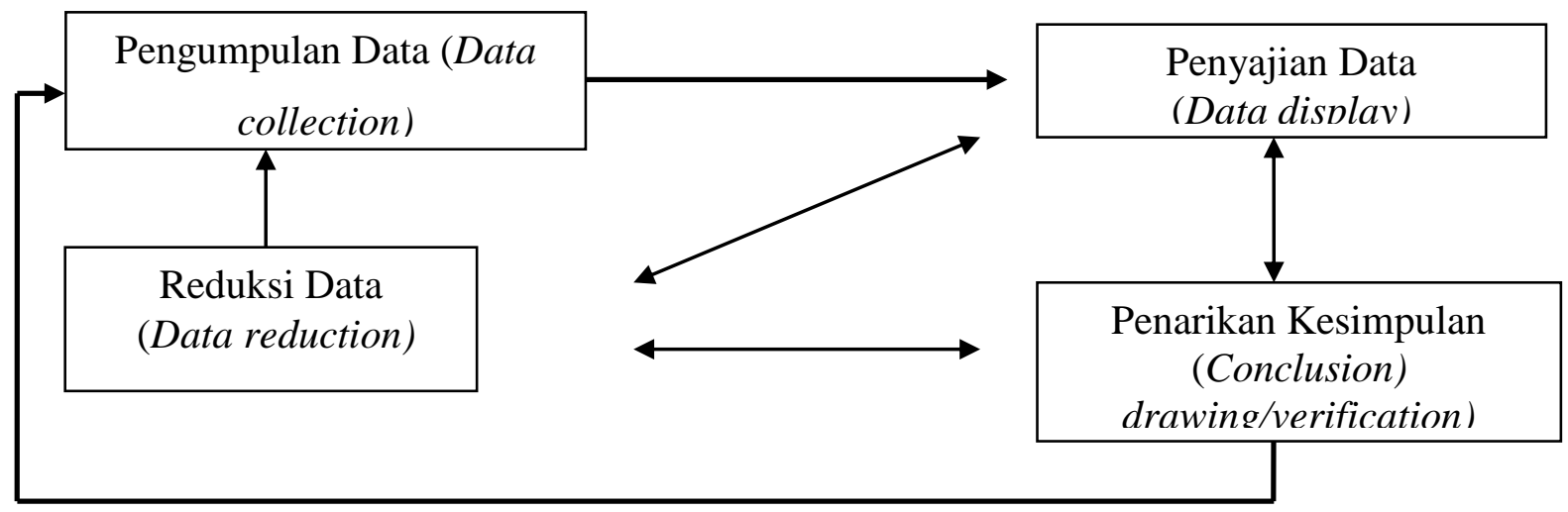

Gambar 3.1 Alur Analisis Data Model Miles and Huberman

\section{HASIL PENELITIAN DAN PEMBAHASAN}

Hasil Penelitian. Berdasarkan data yang di peroleh, jumlah WPOP yang terdaftar di KPP Pratama Bitung adalah sebanyak 102.488 Wajib Pajak.

Dari jumlah tersebut sebagian WP telah melaporkan pajaknya secara online, berikut penjelasannya yang dapat dilihat pada Tabel 1 berikut ini :

Tabel 1. Data Wajib Pajak Orang Pribadi yang menggunakan e-Filing di KPP Pratama Bitung

\begin{tabular}{lll}
\hline Tahun & Jenis SPT & Total \\
\hline 2016 & SPT Tahunan PPh OP S & 15.473 \\
2016 & SPT Tahunan PPh OP SS & 16.901 \\
2017 & SPT Tahunan PPh OP S & 16.095 \\
2017 & SPT Tahunan PPh OP SS & 13.382 \\
\hline
\end{tabular}

Sumber : Data Olahan 2018

Berdasarkan Tabel 1 diatas, data yang di peroleh yaitu jumlah Wajib Pajak Orang Pribadi yang melapor SPT Tahunan PPh OP S pada tahun 2016 adalah sebanyak 15.473 Wajib Pajak, dan SPT Tahunan PPh OP SS pada tahun 2016 adalah sebanyak 16.901. Total pengguna e-filing pada tahun 2016 yaitu 32.374 Wajib Pajak. Kemudian jumlah SPT Tahunan PPh OP S pada tahun 2017 adalah 16.095 dan SPT Tahunan PPh OP SS pada tahun 2017 adalah 13.382. Total pengguna e-Filing pada tahun 2017 adalah 29.477.

Analisis Penerapan e-Filing Pada Wajib Pajak Orang Pribadi di KPP Pratama Bitung. Berdasarkan analisis hasil penelitian maka ditemukan 2 (dua) kendala yaitu : (a) keterbatasan Sumber Daya Manusia; dan (b) sosialisasi perpajakan.

Untuk memperjelas kendala-kendala yang ditemukan maka akan diuraikan sebagai berikut:

Keterbatasan Sumber Daya Manusia. Keterbatasan sumber daya manusia dalam hal ini berhubungan dengan kemampuan Wajib Pajak dalam pelaporan SPT Tahunan secara online. Terbatasnya sumber daya yang dimiliki oleh Wajib Pajak disebabkan oleh kurang pahamnya wajib pajak tentang cara menggunakan komputer, keterbatasan akses internet di daerahdaerah tertentu sehingga wajib pajak kesulitan dalam merekam data. Hal tersebut seperti yang disampaikan beberapa informan berikut ini : 
“...Saya tidak begitu tahu menggunakan komputer, apalagi yang sudah berhubungan dengan internet dan aplikasi-aplikasi online. Bagi saya, lebih baik langsung datang di Kantor Pajak saja, kalau dikantor Pajak bisa dibantu sama aparatur yang ada disana”. (Informan 2).

“...ketika saya mengakses, link e-filing tidak bisa di akses. Loading tidak jalan dan tidak bisa log-in. Saya sudah melakukan berulang kali namun situs DJP tetap tidak bisa dibuka. Saya mencoba menghubungi kring pajak 1500200 namun tidak bisa tersambung. Hal yang sama juga di alami rekan saya, ini disebabkan karena banyaknya wajib pajak yang mengakses link tersebut sehingga server penuh dan sulit untuk di akses. (Informan 3).

“...di daerah tempat saya tinggal jaringannya masih belum stabil, belum lagi jika listrik padam, jaringan internet pun menjadi terganggu. Faktor tersebut membuat saya kesulitan untuk terhubung ke situs pajak online, saya khawatir jika sewaktu-waktu internet mengalami error dan data tidak terekam kemudian hilang. Lagi pula untuk bisa lapor pajak secara online saya harus mengambil kode e-FIN di KPP terlebih dahulu. Jika lapor SPT langsung pakai nomor NPWP itu berarti saya tidak perlu repot lagi ke KPP, namun karena harus ke KPP terlebih dahulu lebih baik saya lapor SPT secara manual saja agar tidak repot dua kali. (Informan 4).

Keterbatasan sumber daya manusia dalam hal ini berhubungan dengan terbatasnya pengetahuan wajib pajak secara pribadi yaitu karena latar belakang yang berbeda-beda dari wajib pajak seperti dari segi pengetahuan dan usia. Wajib pajak yang berlatar belakang pendidikan yang cukup akan lebih mudah memahami sistem perpajakan yang baru selain itu wajib pajak yang sudah berusia lanjut lebih sulit memahami pelaporan pajak secara online.

Terbatasnya akses jaringan internet menjadi faktor penghambat lainnya dalam penerapan $e$-Filing di KPP Pratama Bitung. Internet di Kota Bitung yang masih belum merata dan memadai, sehingga wajib pajak merasa kesulitan mengakses website untuk mengisi formulir SPT secara online. Selain itu banyaknya akses layanan e-Filing pada masa akhir pelaporan pajak membuat jaringan internet menjadi sibuk sehingga server pusat menjadi drop, hal ini kemudian menyebabkan data yang di isi pada formulir SPT tidak terekam sehingga wajib pajak harus berulang kali mengakses e-Filing. Hal-hal yang tidak terpenuhi dalam penerapan $e$-Filing di KPP Pratama Bitung yaitu terbatasnya pengetahuan wajib pajak dan akses jaringan internet. Akibat yang ditimbulkan adalah masyarakat menjadi enggan menggunakan $e$-Filing sebagai pelaporan SPT Tahunan secara online.

Sosialisasi Perpajakan. Sosialisasi perpajakan adalah hal yang penting dalam memperkenalkan e-Filing pada kalangan masyarakat. Kurangnya sosialisasi perpajakan menjadi salah satu faktor yang menghambat kurangnya WP memakai $e$-Filing. Hal tersebut seperti pernyataan dari informan berikut.

“...saya sudah baca di pamflet-pamflet tentang lapor pajak secara online, tapi saya tidak tahu bagaimana caranya. Saya juga belum pernah mendapat sosialisasi dari Kantor Pajak maupun dari instansi saya bekerja, saya pikir mungkin itu hanya salah satu pilihan untuk lapor pajak, lagi pula kan ada kantor pajak saya bisa lapor SPT Tahunan langsung ke Kantor Pajak". (Informan 4).

"...belum paham dan belum mencoba. Saya lebih memilih datang langsung saja ke KPP Pratama Bitung yang kebetulan jaraknya tidak jauh dari kantor saya bekerja”. (Informan 5). 
“...sebatas yang saya ketahui bahwa sekarang bisa lapor pajak secara online, tapi bagaimana cara menggunakannya saya belum tahu. Karena hingga saat ini saya belum mendapat sosialisasi maupun informasi mengenai keuntungan dan kekurangan dari lapor pajak secara online”. (Informan 6)

“...saya sudah tahu bahwa lapor pajak bisa secara online, namun saya belum tertarik menggunakan karena belum tahu caranya, sebatas yang saya tahu lapor pajak secara online agar supaya kita tidak mengantri di Kantor Pajak. Saya belum menerima sosialisasi baik dari pemerintah maupun dari kantor pajak sendiri”. (Informan 7).

Sosialisasi merupakan suatu sarana untuk memperkenalkan suatu sistem baru kepada masyarakat. Hal ini berkaitan dengan kurangnya sosialisasi dari pihak DJP dan KPP Pratama Bitung secara langsung kepada masyarakat. Kurangnya sosialisasi ini menyebabkan wajib pajak tidak tertarik menggunakan e-Filing sebagai pilihan untuk melaporkan SPT Tahunan secara online. Akibatnya jika kurang sosialisasi penggunaan e-Filing, maka dapat mempengaruhi penerapan dan pelaksanaan e-Filing di KPP Pratama Bitung.

\section{KESIMPULAN DAN SARAN}

\subsection{Kesimpulan}

Penggunaan aplikasi e-Filing di KPP Pratama Bitung tahun 2016 sebanyak 32.374 SPT dan tahun 2017 sebanyak 29.477 SPT dari total 102.488 SPT PPh Orang Pribadi di KPP Pratama Bitung. Berdasarkan hasil yang di dapat maka penerapan e-Filing di KPP Pratama Bitung di katakan belum maksimal. Karena wajib pajak masih lebih memilih lapor SPT Tahunan dengan langsung ke KPP.

\subsection{Saran}

Adapun saran yang dapat dijadikan unutk bahan pertimbangan untuk KPP Pratama Bitung.

a. Sebaiknya KPP Pratama Bitung memberi pedoman kepada wajib pajak tentang cara memakai $e$-Filing sehingga WP menjadi penasaran untuk menggunakan $e$-Filing sebagai pelaporan SPT Tahunannya.

b. Sebaiknya pihak KPP Pratama Bitung meningkatkan sosialisasi secara bertahap kepada masyarakat baik di kantor instansi pemerintah dan umum, agar nantinya wajib pajak memperoleh pengetahuan tentang e-Filing serta mengetahui keuntungan dari pelaporan SPT secara online. Selain itu sosialisasi perpajakan dapat dilakukan melalui seminar, atau dapat di informasikan melalui media elektronik dan media masa yang di adakan oleh Direktorat Jendral Pajak yang dapat meningkatkan minat masyarakat dalam menggunakan e-Filing.

\section{DAFTAR PUSTAKA}

Agoes, Sukrisno, (2014), Akuntansi Perpajakan, Edisi 3, Jakarta : Salemba Empat.

Abdul Rahman. 2010. Panduan Pelaksanaan Administrasi Pajak: Untuk Karyawan, Pelaku Bisnis dan Perusahaan. Bandung. Nuansa.

Abdul Wahab, Solichin 2008. Analisis Kebijaksanaan Dari Formulasi ke Implementasi Kebijaksanaan Negara. Edisi Kedua. Jakarta PT. Bumi Aksara

Diana Sari. 2013, Konsep Dasar Perpajakan. Bandung Refika Aditama.

Direktorat Jenderal Pajak. 2004. Keputusan Direktur Jenderal Pajak Nomor KEP- 88/PJ/2004 tentang Penyampaian Surat Pemberitahuan secara Elektronik, Jakarta.

Direktorat Jenderal Pajak. 2014. Peraturan Direktur Jenderal Pajak Nomor 1/PJ/2014 tentang Tata Cara Penyampaian Surat Pemberitahuan Tahunan bagi Wajib Pajak Orang Pribadi 
yang menggunakan Formulir 1770 S atau 1770SS secara e-Filing melalui website Direktorat Jenderal Pajak

Direktorat Jenderal Pajak, Undang-Undang Nomor 16 Tahun 2009 Tentang Perubahan Ketiga Atas Undang-Undang Nomor 6 Tahun 1983 Tentang Ketentuan Umum dan Tata Cara Perpajakan.

Hans Kartikahadi., dkk. 2016. Akuntansi Keuangan Menengah Berbasis PSAK (Buku 1). Jakarta: Salemba Empat.

Hasibuan, Malayu S.P. 2016. Manajemen Sumber Daya Manusia. Edisi Revisi. Jakarta : Penerbit PT Bumi Aksara.

Kuncoro, Mudrajat. 2013 .Metode Riset untuk Bisnis dan Ekonomi, Edisi Keempat, Jakarta, Erlangga.

Siti Resmi, 2014. Perpajakan Teori dan Kasus Edisi 4. Jakarta : Salemba Empat

Republik Indonesia, Pasal 1, angka 11 Undang-Undang Nomor 28 Tahun 2007 Tentang Ketentuan Umum dan Tata cara Perpajakan.

Miles dan Huberman. 2012. Analisa Data Kualitatif. UI Press. Jakarta

Nazir. 2014. MetodePenelitian. Bogor. Ghalia Indonesia.

Sugeng Wahono 2012. Mengurus Pajak Itu Mudah. PT. Elex Media. Jakarta.

Sugiyono. 2015. Metode Penelitian (PendekatanKuantitatif,Kualitatif dan R\&D). Penerbit CV. Alfabeta, Bandung.

Surat Edaran: Direktorat Jenderal Pajak. Surat Edaran Menteri PAN-RB Nomor. 8 Tahun 2015 Tentang Kewajiban Penyampaian Surat Pemberitahuan Tahunan Pajak Penghasilan Wajib Pajak Orang Pribadi Oleh Aparatur Sipil Negara/ Anggota Tentara Nasional Indonesia/ Kepolisian Republik Indonesia Melalui $e$-Filing.

Tumuli, Apriliani K., Sondakh, Jullie J., Wokas, Heince RN. 2016. Analisis Penerapan ESPT dan E-Filing Dalam Upaya Peningkatan Kepatuhan Wajib Pajak (Studi Kasus di Kantor Pelayanan Pajak Pratama Manado). Jurnal EMBA Vol.4 No.3 September 2016. Hal 102-112.

Waluyo. 2014. Perpajakan Indonesia. Jakarta : Salemba Empat.

Yogatama, Arya. 2014. Analisis Faktor-Faktor yang Mempengaruhi Kepatuhan Wajib Pajak Orang Pribadi (Studi di Wilayah KPP Pratama Semarang Candisari). Semarang. 